\title{
Genome-wide identification and functional analyses of calmodulin genes in Solanaceous species
}

Yuan Zhao' ${ }^{1}$ Wei Liu' ${ }^{1}$ You-Ping Xu², Jia-Yi Cao' ${ }^{1}$ Janet Braam³ and Xin-Zhong Cai ${ }^{1 *}$

\begin{abstract}
Background: Calmodulin (CaM) is a major calcium sensor in all eukaryotes. It binds calcium and modulates the activity of a wide range of downstream proteins in response to calcium signals. However, little is known about the CaM gene family in Solanaceous species, including the economically important species, tomato (Solanum lycopersicum), and the gene silencing model plant, Nicotiana benthamiana. Moreover, the potential function of CaM in plant disease resistance remains largely unclear.

Results: We performed genome-wide identification of CaM gene families in Solanaceous species. Employing bioinformatics approaches, multiple full-length CaM genes were identified from tomato, N. benthamiana and potato (S. tuberosum) genomes, with tomato having 6 CaM genes, $N$. benthamiana having 7 CaM genes, and potato having 4 CaM genes. Sequence comparison analyses showed that three tomato genes, S/CaM3/4/5, two potato genes StCaM2/3, and two sets of $N$. benthamiana genes, NbCaM1/2/3/4 and NbCaM5/6, encode identical CaM proteins, yet the genes contain different intron/exon organization and are located on different chromosomes. Further sequence comparisons and gene structural and phylogenetic analyses reveal that Solanaceous species gained a new group of CaM genes during evolution. These new CaM genes are unusual in that they contain three introns in contrast to only a single intron typical of known CaM genes in plants. The tomato CaM (S/CaM) genes were found to be expressed in all organs. Prediction of cis-acting elements in $5^{\prime}$ upstream sequences and expression analyses demonstrated that S/CaM genes have potential to be highly responsive to a variety of biotic and abiotic stimuli. Additionally, silencing of S/CaM2 and S/CaM6 altered expression of a set of signaling and defense-related genes and resulted in significantly lower resistance to Tobacco rattle virus and the oomycete pathogen, Pythium aphanidermatum.

Conclusions: The CaM gene families in the Solanaceous species tomato, N. benthamiana and potato were identified through a genome-wide analysis. All three plant species harbor a small set of genes that encode identical CaM proteins, which may manifest a strategy of plants to retain redundancy or enhanced quantitative gene function. In addition, Solanaceous species have evolved one new group of CaM genes during evolution. CaM genes play important roles in plant disease resistance to a variety of pathogens.
\end{abstract}

Keywords: Calcium, Calmodulin, Gene Structure, Phylogenetic Analysis, Defense, Resistance, Tomato, Nicotiana Benthamiana, Potato

\footnotetext{
* Correspondence: xzhcai@zju.edu.cn

${ }^{1}$ Institute of Biotechnology, College of Agriculture and Biotechnology,

Zhejiang University, 866 Yu Hang Tang Road, Hangzhou 310058, China

Full list of author information is available at the end of the article
} 


\section{Background}

Calcium $\left(\mathrm{Ca}^{2+}\right)$ is an essential element in plant cell wall and an important nutrient for plant growth. In addition, $\mathrm{Ca}^{2+}$ acts as a second messenger to regulate a variety of biological processes in response to various biotic and abiotic stimuli in eukaryotic organisms [1-4].

Calmodulin $(\mathrm{CaM})$ is a major $\mathrm{Ca}^{2+}$ sensor thought to interpret $\mathrm{Ca}^{2+}$ signatures in plants. It is a small protein, typically comprising only about 149 amino acids. It bears four helix-loop-helix motifs called EF hands, each with the ability to bind $\mathrm{Ca}^{2+}[5]$.

CaM genes have been identified in several plant species. Genome-wide identification of CaM genes in model plant species, such as Arabidopsis and rice [5-7], has revealed that $\mathrm{CaM}$ proteins are typically encoded by gene families. In addition, plants may contain several CaM isoforms that differ in only a few amino acids, with one of the isoforms being encoded by several genes located on different chromosomes of the genome. For example, in Arabidopsis, seven genes encode for four CaM isoforms, among which CaM1 and CaM4 encode an identical protein sequence and CaM2, CaM3 and CaM5 also encode an identical protein sequence, differing in only a few amino acids from the CaM1/CaM4 isoform. The four Arabidopsis CaM isoforms differ from each other in only one to five amino acids [5]. In rice, five genes encode three $\mathrm{CaM}$ isoforms. OsCaM1-1, OsCaM1-2 and OsCaM1-3 encode an identical protein sequence. OsCaM2 and OsCaM3 proteins have only two amino acid differences. In addition, CaM genes have been identified in other plant species, such as tobacco [8], potato [9] and soybean [10]. Nevertheless, CaMs in many Solanaceous species, including the economically important species tomato and the model species for gene silencing studies, Nicotiana benthamiana, have not yet been identified or characterized. Genome-wide analysis of CaM gene families in other Solanaceous species has also not yet been conducted.

As major $\mathrm{Ca}^{2+}$ sensors, CaMs are multifunctional in plants. CaMs play important roles in regulation of growth, development and abiotic stress resistance in plants $[11,12]$. For example, over-expression of AtCaM7 in Arabidopsis promotes photomorphogenetic growth [13]. A loss-of -function mutation in AtCaM2 causes a significant reduction in pollen germination [14]. In marigold, CaM regulates adventitious root development [15]. Over-expression of OsCaM1, MCaM3 and GmCaM4 in rice, mulberry and soybean, respectively, enhances resistance to drought and/ or salt [16-19].

Limited evidence has been reported for a role of CaM in plant disease resistance. Ectopic over-expression of the soybean CaM genes, SCaM4 and SCaM5, enhances resistance to Phytophthora parasitica var. nicotianae, Pseudomonas syringae pv. tabaci and TMV in transgenic tobacco [20] and to $P$. syringae pv. tomato DC3000 in transgenic
Arabidopsis [21]. Over-expression of CaCaM1 promotes reactive oxygen species (ROS) and nitric oxide (NO) generation, and increases resistance to Xanthomonas campestris pv. vesicatoria in pepper [22]. Knockdown of NtCaM13 expression enhances susceptibility to Ralstonia solanacearum and Rhizoctonia solani in tobacco [23]. CaM may directly bind with CAMTA3/SR1, which binds to and negatively regulates EDS1, and thus down-regulate salicylic acid dependent defense and resistance [24]. Different isoforms of a CaM family may play various roles in the regulation of plant defense [25].

Taking advantage of the recent release of complete genomes of a number of Solanaceous species, we performed a genome-wide identification of $C a M$ gene families in tomato, $N$. benthamiana and potato. Through systemic phylogenetic, gene structure and expression analyses, we discovered one novel group of CaM genes in Solanaceous species, and demonstrated that a small set of genes encode an identical CaM protein sequence, as may be typical of plants [5-7]. Multiple genes encoding identical proteins may ensure redundancy for a critical life function or may be needed to produce sufficient protein product. Alternatively, multiple CaM genes may be evidence of a strategy of plants to efficiently evolve functional gene paralogs. Finally, we provide evidence that reveals function for SlCaMs in resistance to viral and oomycete pathogens.

\section{Results}

\section{Identification of CaM genes in Solanaceous genomes}

To identify CaM genes in genomes of Solanaceous species, all four Arabidopsis and three rice CaM protein sequences were collected and used for TBLASTN search against the databases from SGN (http://solgenomics.net/). Seventy three, 96 and 81 nonreduntant sequences were retrieved in tomato, potato (S. tuberosum) and Nicotiana benthamiana genomes, respectively. These sequences were aligned with the canonical Arabidopsis CaM (AtCaM2) with CLUSTALX program and viewed by GeneDoc for the sequence identity to AtCaM2. Sequences were further analyzed by Pfam (http://pfam.sanger.ac.uk/) and CDD (http://www.ncbi.nlm.nih.gov/cdd) programs to confirm presence of the EF-hand domains, a characteristic domain for $\mathrm{Ca}^{2+}$ binding. Genes with sequence identity of over $90 \%$ to AtCaM2 and that harbored four EF-hands were defined as CaMs, following precedent set previously [5]. The genomic, cDNA and protein sequences were comparatively analyzed for all these CaM candidates. We found that the cDNA and protein sequences of one of the $N$. benthamiana CaMs (NbS00037851g0005.1) previously deposited in the database were incorrect due to an error in identification of the second intron. The sequences have been corrected (Table 1, Figures 1 and 2). Finally, six, four and seven full-length $\mathrm{CaM}$ genes were indentified in tomato, potato and $N$. benthamiana genomes. To better 
Table 1 The CaM gene families in Solanaceous species

\begin{tabular}{|c|c|c|c|c|c|c|c|c|c|c|c|}
\hline $\begin{array}{l}\text { CaM } \\
\text { Gene }\end{array}$ & Locus number $^{1}$ & $\begin{array}{l}\text { Chromosome/ } \\
\text { location }\end{array}$ & $\begin{array}{c}E F \\
\text { hands }\end{array}$ & $\begin{array}{l}\text { Protein } \\
\text { size (aa) }\end{array}$ & $\begin{array}{l}\text { Mol Wt } \\
(\mathrm{kDa})\end{array}$ & pl & Intron & $\begin{array}{l}\% \text { of } \\
\text { Met }\end{array}$ & Cys $27^{2}$ & $K 116^{3}$ & $\begin{array}{l}\% \text { amino acid identity } \\
\text { to canonical CaM }\end{array}$ \\
\hline SICaM1 & Solyc01g008950.2.1 & $\begin{array}{l}\text { ch1/2963201- } \\
2960056\end{array}$ & 4 & 149 & 16.85 & 3.95 & 1 & 6.0 & + & + & $98 \%$ \\
\hline SICaM2 & Solyc10g081170.1.1 & $\begin{array}{l}\text { ch10/ } \\
61628347- \\
61626964\end{array}$ & 4 & 149 & 16.85 & 3.95 & 1 & 6.0 & + & + & $99 \%$ \\
\hline SICaM3 & Solyc10g077010.1.1 & $\begin{array}{l}\text { ch10/ } \\
59260504- \\
59262472\end{array}$ & 4 & 149 & 16.83 & 3.93 & 1 & 6.0 & + & + & Cannonical SICaM \\
\hline SICaM4 & Solyc11g072240.1.1 & $\begin{array}{l}\text { ch11/ } \\
52540732- \\
52538666\end{array}$ & 4 & 149 & 16.83 & 3.93 & 1 & 6.0 & + & + & Cannonical SICaM \\
\hline SICaM5 & Solyc12g099990.1.1 & $\begin{array}{l}\text { ch12/ } \\
65252546- \\
65249443\end{array}$ & 4 & 149 & 16.83 & 3.93 & 1 & 6.0 & + & + & Cannonical SICaM \\
\hline SICaM6 & Solyc03g098050.2.1 & $\begin{array}{l}\text { ch3/53844509- } \\
53847335\end{array}$ & 4 & 149 & 16.93 & 4.00 & 3 & 6.0 & + & + & $91 \%$ \\
\hline $\mathrm{NbCaM1}$ & NbS00008025g0011.1 & - & 4 & 149 & 16.85 & 3.95 & 1 & 6.0 & + & + & Cannonical NbCaM \\
\hline $\mathrm{NbCaM} 2$ & NbS00010343g0006.1 & - & 4 & 149 & 16.85 & 3.95 & 1 & 6.0 & + & + & Cannonical NbCaM \\
\hline NbCaM3 & NbS00055418g0001.1 & - & 4 & 149 & 16.85 & 3.95 & 1 & 6.0 & + & + & Cannonical NbCaM \\
\hline $\mathrm{NbCaM} 4$ & $\begin{array}{l}\text { Corrected form of } \\
\text { NbS00037851g0005.1 }\end{array}$ & - & 4 & 149 & 16.85 & 3.95 & 1 & 6.0 & + & + & Cannonical NbCaM \\
\hline NbCaM5 & NbS00051963g0003.1 & - & 4 & 149 & 16.83 & 3.93 & 1 & 6.0 & + & + & $99 \%$ \\
\hline $\mathrm{NbCaM6}$ & NbS00061039g0001.1 & - & 4 & 149 & 16.83 & 3.93 & 1 & 6.0 & + & + & $99 \%$ \\
\hline NbCaM7 & NbS00041363g0012.1 & - & 4 & 149 & 16.85 & 3.98 & 1 & 6.0 & + & + & $99 \%$ \\
\hline StCaM1 & PGSC0003DMC400039343 & - & 4 & 149 & 16.85 & 3.95 & 1 & 6.0 & + & + & $99 \%$ \\
\hline StCaM2 & PGSC0003DMC400047620 & - & 4 & 149 & 16.83 & 3.93 & 1 & 6.0 & + & + & Cannonical StCaM \\
\hline StCaM3 & PGSC0003DMP400012777 & - & 4 & 149 & 1.683 & 3.93 & 1 & 6.0 & + & + & Cannonical StCaM \\
\hline StCaM4 & PGSC0003DMP400056198 & - & 4 & 149 & 1.693 & 4.00 & 3 & 6.0 & + & + & $91 \%$ \\
\hline
\end{tabular}

${ }^{1} \mathrm{NbCaM} 4$ was deduced from the genomic sequence Niben044Scf00037851 and was the corrected form of NbS00037851g0005.1.

2 Presence of a cysteine at the position of 27 in a CaM protein was indicated as a "+".

${ }^{3}$ Presence of a lysine at the position of 116 in a CaM protein was indicated as a " + ".

reflect the orthologous relationship between the Solanaceous and Arabidopsis CaM genes, we named the Solanaceous CaM members in accordance with their phylogenies and sequence similarity to individual AtCaMs (Table 1).

Sequence analyses showed that all Solanaceous CaM proteins are comprised of 149 amino acids (Table 1). Motif analysis using Pfam and CDD revealed that all of the Solanaceous CaMs carry two pairs of EF-hand domain, corresponding to two EF-hand 7 motifs (PF13499). Sequence alignment using ClustalX demonstrated that members of the Solanaceous CaM families are highly conserved in amino acid sequence, with over $90 \%$ sequence identity (Figure 1). The tomato CaMs encoded by SlCaM3, SlCaM4 and SlCaM5 are identical in amino acid sequence while the other three SICaM proteins share 91\%-99\% amino acid sequence identity with SlCaM3/4/5. The potato StCaM2 and StCaM3 protein sequences are identical while StCaM1 and StCaM4 share 99\% and 91\% amino acid identity with StCaM2/
3 , respectively. In the case of $N$. benthamiana CaMs, NbCaM1, NbCaM2, NbCaM3, and NbCaM4 encode an identical protein sequence, and $\mathrm{NbCaM5}$ and NbCaM6 encode an identical protein also. The other two $\mathrm{NbCaMs}$ exhibit $99 \%$ sequence identity to NbCaM1/ 2/3/4 (Table 1, Figure 1). However, nucleotide sequences of the CaM gene families are much more diverse in comparison with protein sequences. The identity percentage of nucleotide sequences within a $\mathrm{CaM}$ gene family is $79 \%$ 92\% for $\mathrm{SlCaMs}, 79 \%-91 \%$ for StCaMs and $83 \%-98 \%$ for $\mathrm{NbCaMs}$, respectively (Additional file 1). Notably, even the genes that encode identical $\mathrm{CaM}$ protein sequences are not identical. For example, the coding sequences of SlCaM3/4/5, StCaM2/3, NbCaM1/2/3/4 and NbCaM5/6 share only $88 \%-92 \%, 86 \%, 83 \%-96 \%$ and $99 \%$, respectively (Figure 2). These genes differ primarily in the third nucleotide of the amino acid coding triplets (Figure 2).

In addition to the CaM genes described above, 67, 77 and 89 other sequences of tomato, potato and $N$. benthamiana respectively, were retrieved from BLAST searches using 


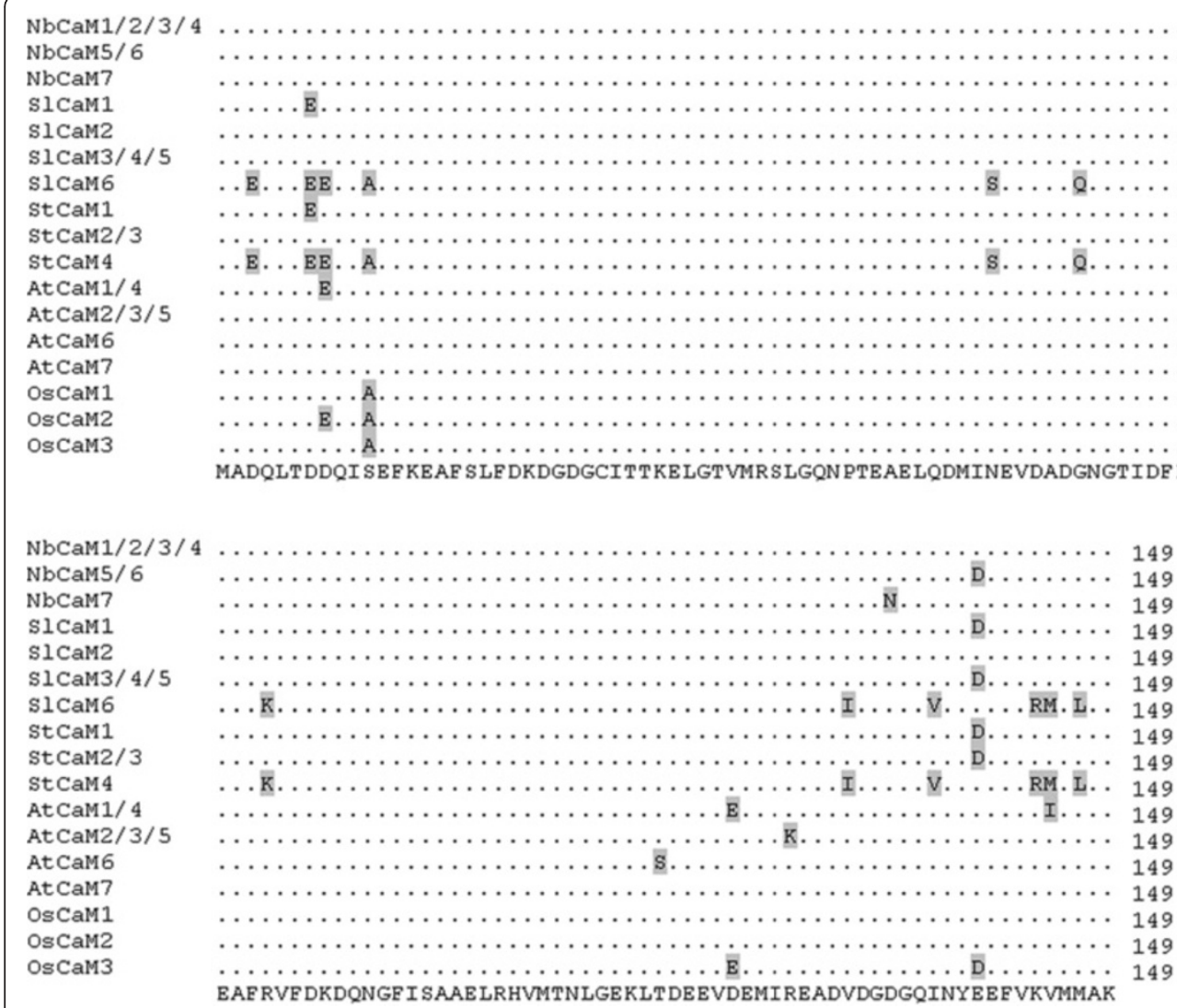

Figure 1 Alignment profile of CaM proteins of Solanaceous species, Arabidopsis and rice. The accession numbers for CaM proteins of tomato, potato and Nicotiana benthamiana were listed at Table 1 while those for Arabidopsis and rice CaM proteins were as follows: AtCaM1 (AT5G37780.1), AtCaM2 (AT2G41110.1), AtCaM3 (AT3G56800.1), AtCaM4 (AT1G66410.1), AtCaM5 (AT2G27030.1), AtCaM6 (AT5G21274.1), AtCaM7 (AT3G43810.1), OsCaM1 (LOC_Os03g20370.1, LOC_Os07g48780.1, LOC_Os01g16240.1), OsCaM2(LOC_Os05g41210.1), OsCaM3(LOC_Os01g17190.1).

Arabidopsis and rice CaMs (Additional file 2). Of these sequences, 33, 46 and 55 sequences of tomato, potato and $N$. benthamiana respectively, are shorter than 200 amino acids long and contain EF-hands but no any other known functional domain. These protein sequences were thus designated as Solanaceous calmodulin-like (CML) sequences, following the criteria used previously [4]. Of the remaining sequences, 29 tomato, 30 potato and $34 N$. benthamiana sequences were longer than canonical CaMs, having more than 500 amino acids, and harbor not only EF-hand domains but also protein kinase domain(s); these may be calcium-dependent protein kinase candidates.

\section{Gene structure and chromosome location of Solanaceous CaM genes}

The finding that several genes encode identical CaM proteins in a variety of Solanaceous species prompted us to investigate gene structure and chromosome location of these CaM genes in the different species. Results of comparisons of genomic DNA sequences with corresponding cDNA sequences showed that coding sequences of $\mathrm{CaM}$ genes are interrupted by introns. It is noteworthy that unlike Arabidopsis CaM genes, which carry a single intron, the number of introns varied in Solanacous CaM genes, with one in SlCaM1 to SlCaM5, StCaM1 to StCaM3 and all seven $\mathrm{NbCaMs}$, and three introns in SlCaM6 and StCaM4 (Table 1 and Figure 3). Interestingly, all Solanaceous CaM genes were disrupted by the first intron in the Gly26 codon, similar to that previously reported for Arabidopsis CaMs [5]. For those genes that contain 3 introns, the interruption sites by the 2nd and 3rd introns were Asp70 and Leu106 codons, respectively. The intron that interrupted Gly26 codon was phase 1 type, while the other two belonged to phase 0 type (Figure 3). In addition, generally, the sizes of the introns are significantly longer in Solanaceous CaMs compared with Arabidopsis CaMs, but are similar in length to rice CaMs (Figure 3).

Chromosome localization analysis demonstrated that the SlCaM genes are located on different chromosomes of the tomato genome. Both SlCaM2 and SlCaM3 are located on chromosome 10, while the other four SlCaM genes are on four different chromosomes (1, 3, 11 and 12), respectively (Table 1 ). Information about the chromosome 


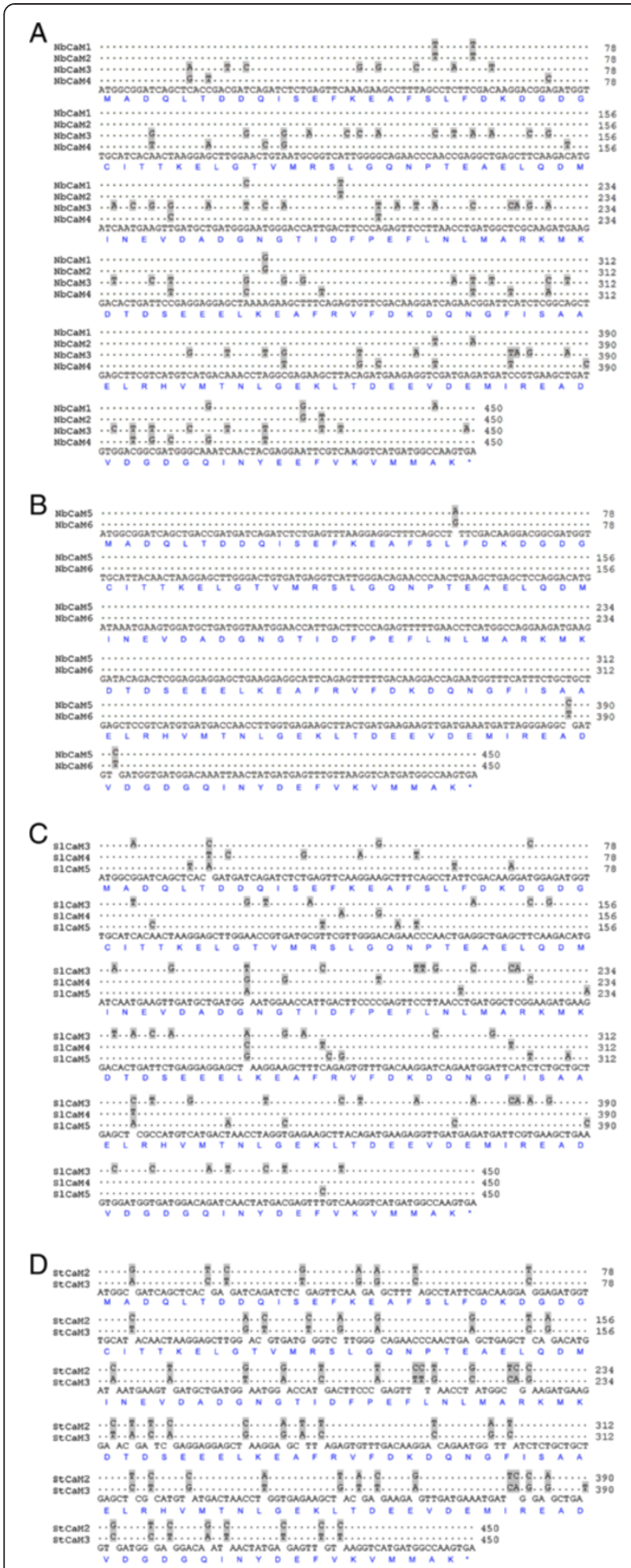

Figure 2 Alignment profile of the Solanaceous CaM genes that encode an identical protein isoform. Coding sequences of NbCaM1/2/3/4 (A), NbCaM5/6 (B), S/CaM3/4/5 (C) and StCaM2/3 (D) were aligned. The corresponding amino acid sequences are also shown. location of CaMs in other Solanaceous species is not yet available.

\section{Phylogenetic relationship among Solanaceous and Arabidopsis and rice CaM proteins}

The full-length amino acid sequences of Solanaceous and Arabidopsis and rice CaMs were subjected to phylogenetic analysis. A maximum likelihood (ML) phylogenetic tree was constructed. The CaM proteins clustered into two major groups (Figure 4). Most Solanaceous CaMs belonged to the same group, named Group I here. These included 5 out of 6 SlCaMs; 3 out of 4 StCaMs and all 7 NbCaMs. All five Arabidopsis and three rice CaMs also belonged to Group I. However, two Solanaceous CaMs, SlCaM6 and StCaM4 segregated into another group (Group II) (Figure 4). It is intriguing that the Solanaceous, Arabidopsis and rice CaMs formed different groups. All Arabidopsis and rice CaMs were contained into the same group (Group I), while the Solanaceous CaMs were separated into two groups (Groups I and II), among which the group II was newly expanded (Figure 4). The $\mathrm{CaM}$ genes encoding Group II proteins carry three introns while those genes encoding Group I proteins contain only one (Figure 3), supporting the phylogenetic classification into two CaM groups. These data revealed that the Solanaceous species have evolved a new type of CaM during the evolution.

\section{Bioinformatics prediction of potential cis regulatory sequences for SICaM gene expression}

The $5^{\prime}$ upstream noncoding sequences of the CaM genes encoding identical CaM proteins are not well conserved (data not shown), suggesting that these genes may be differentially expressed in response to various stimuli, even though they encode identical proteins.

To obtain hints for how expression of the CaM genes may be regulated, potential cis-acting elements in upstream 1000 bp sequences of the SlCaM genes were analyzed. PLACE analysis revealed that SlCaM gene upstream sequences carry a variety of potential cis-acting elements, including binding sites for transcription factors that are regulated by hormones such as abscisic acid (ABA), gibberellin (GA), auxin, jasmonic acid (JA) and ethylene (ETH). The patterns of cis-acting elements differed significantly among the SlCaM genes. The SlCaM1 gene promoter contained 15 elements that may respond to all these five hormones, while all other SlCaMs lacked elements responsive to one or several hormones. SlCaM4 lacked ciselements predicted to be responsive to auxin and ethylene, SlCaM2, SlCaM5 and SlCaM6 contained elements known to be responsive to two hormones, while $\mathrm{SlCaM} 3$ carried only cis-elements responsive to auxin. In addition, all the SlCaM upstream sequences carry an abundance of W-box 


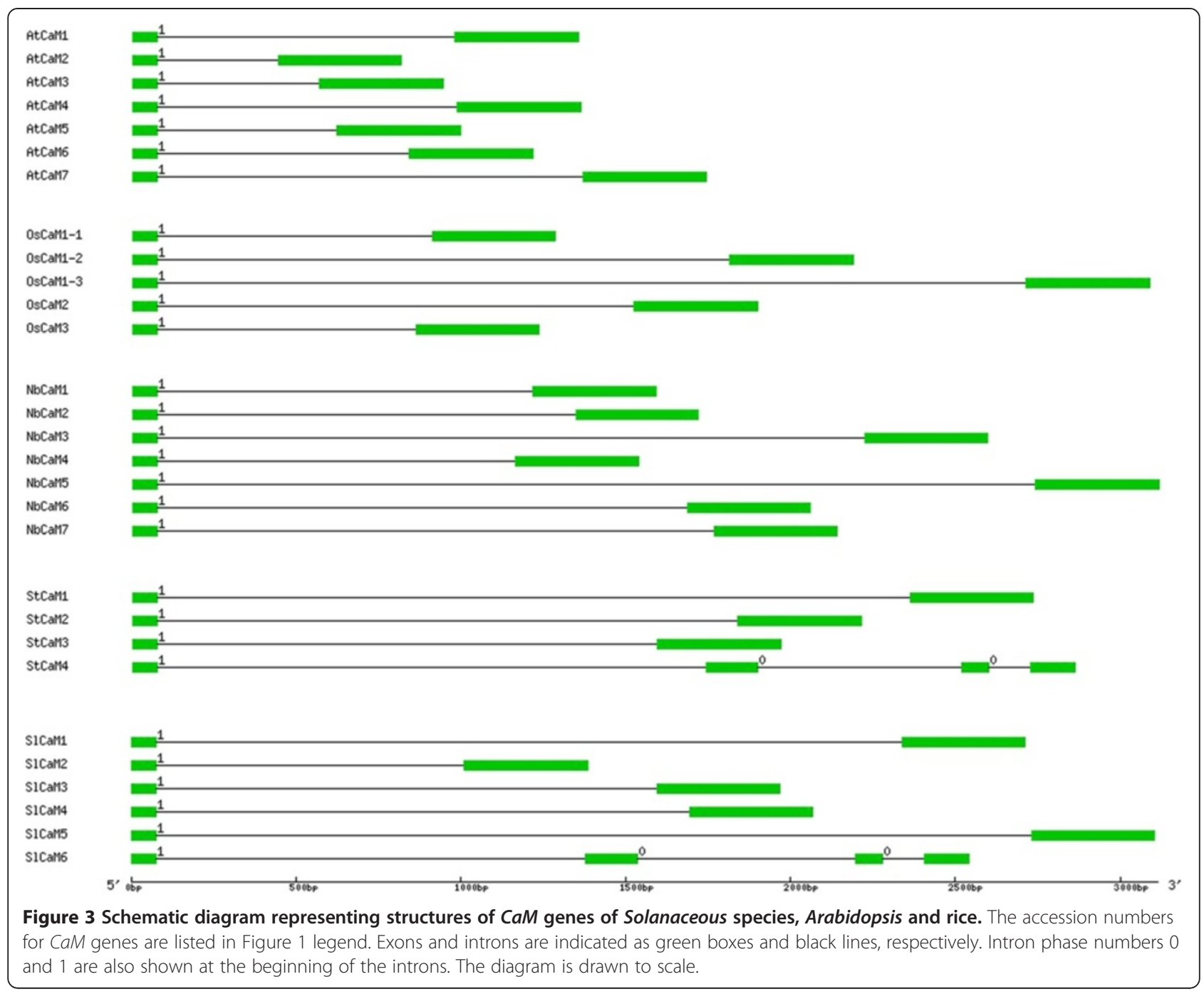

elements, suggesting that $S l C a M$ expression may be regulated by the WRKY transcription factors (Table 2).

\section{Expression of SICaM genes in plants was organ-specific}

The six SlCaM genes encode four CaM isoforms (Figures 1 and 2). To examine whether these genes are differentially expressed in developing plants and thus potentially harboring differential physiological functions, qRT-PCR analysis was conducted using SlCaM gene specific primers (Table 3). The expression patterns of SlCaM genes in roots, stems, leaves, flowers and fruit organs are shown in Figure 5A. Results of qRT-PCR expression analysis revealed that all $S l C a M$ genes were constitutively expressed in all organs examined. However, the levels of expression were distinct in the various organs. Among the SlCaMs, SlCaM1 displayed the lowest expression level in all organs. SlCaM4 also showed relatively low expression in all organs except flowers. SlCaM2 exhibited the highest transcript accumulation level in all organs except fruits.
SlCaM3 was expressed modestly in roots, stems and leaves, but was highly expressed in fruits and flowers. Expression profiles of SlCaM5 were similar to that of SlCaM3, although the absolute expression level was relative lower. SlCaM6 was expressed highly in roots, fruits and flowers, and modestly in stems and leaves. Thus, SlCaM3, SlCaM4 and SlCaM5 genes, which encode an identical protein, showed different expression levels in the various organs (Figure 5A). Generally speaking, the $S l C a M$ genes were expressed highest in flowers and lowest in stems (Figure $5 \mathrm{~A}$ ).

\section{Expression of SICAM genes was highly responsive to diverse stimuli}

To gain further information about potential differential gene functions, SlCaM expression patterns in response to various plant hormones were investigated. Expression data demonstrated that SlCaM2 to SlCaM6 showed similar expression patterns in response to ETH, BTH and JA, which 


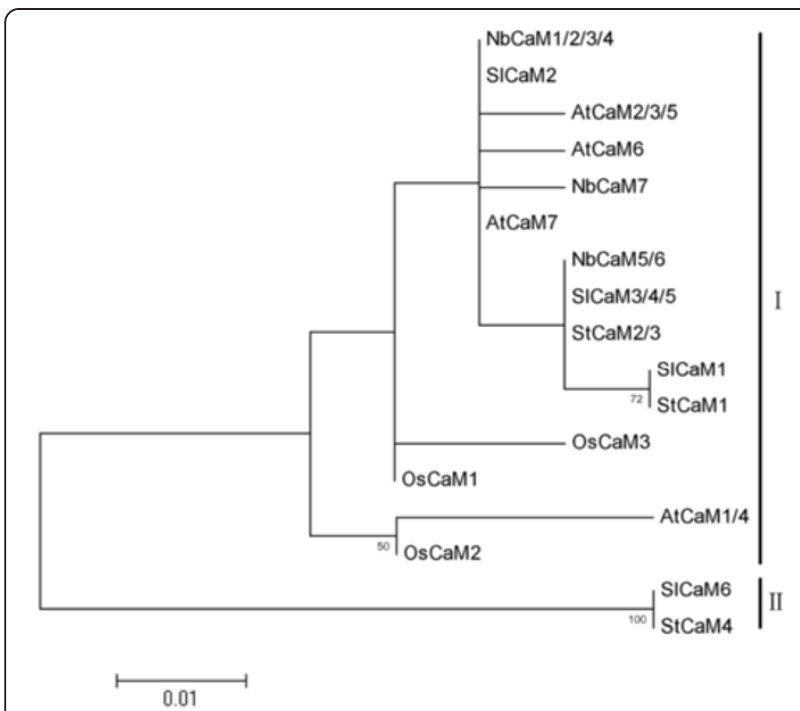

Figure 4 Phylogenetic tree for CaM proteins of Solanaceous species, Arabidopsis and rice. A CaM protein that is encoded by more than one gene is named as a combination of all the gene numbers. The accession numbers for the CaMs are listed in Figure 1 legend.

was, however, different from that of SlCaM1 in expression level (Figure 5B). Expression of SlCaM2 to SlCaM6 was dramatically up-regulated with ETH treatment as early as 4 hpt (hours post treatment) and then maintained the elevated expression level, moderately up-regulated with $\mathrm{BTH}$ treatment at $12 \mathrm{hpt}$, while strongly down-regulated with JA treatment after $4 \mathrm{hpt}$. Expression of SlCaM1 showed a similar trend but had a significant different magnitude in response to these three hormones in comparison with
SlCaM2 to SlCaM6. SlCaM1 was very highly up-regulated at 12 hpt by ETH and BTH treatments and downregulated to undetectable levels at 4 hpt by JA treatment. Regarding ABA treatment, the six SlCaM genes exhibited different responses, although the alteration magnitude was generally not as large as that in response to other tested hormones. Expression of SlCaM2 to SlCaM4 was downregulated, whereas SlCaM1, SlCaM5 and SlCaM6 expression was up-regulated at $4 \mathrm{hpt}$ and then down-regulated at $12 \mathrm{hpt}$ (Figure 5B). These data indicate that SlCaMs might play different roles in regulation of various hormone-regulated biological processes.

To determine whether there are roles for SlCaM gene function in disease resistance, gene expression in response to a set of pathogens was examined. Expression of SlCaM genes varied in response to inoculation with different pathogens (Figure 5C). Expression of SlCaM2 to SlCaM6 was significantly reduced at $4 \mathrm{~h}$ and then increased at $12 \mathrm{~h}$ after inoculation with Pseudomonas syringae pv. tomato DC3000 (Pst DC3000), whereas expression of SlCaM1 was down-regulated to undetectable levels since $4 \mathrm{~h}$ after inoculation (Figure 5C). However, expression of all SlCaM genes was continuously up-regulated after inoculation with Xanthomonas oryzae pv. oryzae (Xoo). Among the SlCaM genes, expression of SlCaM2 was most induced at $12 \mathrm{~h}$ after Xoo inoculation (Figure 5C). These data indicate that SlCaMs might be involved in regulation of plant disease resistance.

Collectively, in general, SlCaM1 expression was much more sensitive to hormone treatment and pathogen inoculation in comparison with expression of the other SlCaMs.

Table 2 The cis-acting elements in SICaM gene promoters

\begin{tabular}{|c|c|c|c|c|c|c|c|c|}
\hline \multirow[t]{2}{*}{ Regulator } & \multirow{2}{*}{$\begin{array}{l}\text { Cis-acting } \\
\text { element }\end{array}$} & \multirow[t]{2}{*}{ Code } & \multicolumn{6}{|c|}{ Number of elements } \\
\hline & & & SICaM1 & SICaM2 & SICaM3 & SICaM4 & SICaM5 & SICaM6 \\
\hline \multirow[t]{5}{*}{ ABA } & ABRELATERD & S000414 & 4 & & & 5 & & 1 \\
\hline & ABRERATCAL & S000507 & 1 & & & & & 1 \\
\hline & DPBFCOREDCDC & S000292 & 1 & & & & 1 & \\
\hline & MYCATRD22 & S000174 & 2 & & & & & \\
\hline & PYRIMIDINEBOXH & S000298 & 1 & & & 1 & & \\
\hline \multirow[t]{2}{*}{ GA } & TATCCAOSAMY & S000403 & 1 & & & 1 & & 2 \\
\hline & PYRIMIDINEBO & S000298 & 1 & & & 1 & & \\
\hline ETH & ERELEE4ERE & S000037 & 1 & 1 & & & & \\
\hline Auxin & NTBBF1ARROL & S000273 & 2 & 2 & 2 & & 1 & \\
\hline$J A$ & T/GBOXATPIN2 & S000458 & 1 & & & 2 & & \\
\hline \multirow[t]{3}{*}{ WRKY transcription factor } & WBOXNTERF3 & S000457 & 4 & 3 & 3 & 3 & 4 & 3 \\
\hline & WRKY71OS & S000447 & 10 & 3 & 3 & 11 & 9 & 6 \\
\hline & WBOXATNPR1 & S000390 & 1 & & 2 & 4 & 4 & 2 \\
\hline
\end{tabular}


Table 3 Primers used for qRT-PCR gene expression analyses

\begin{tabular}{|c|c|}
\hline Primer name & Sequence $\left(5^{\prime} \rightarrow 3^{\prime}\right)$ \\
\hline SICaM1-F & TTCCATTTCAAAGTATCTC \\
\hline SICaM1-R & GGTCCCATTTCCATCAGCA \\
\hline SICaM2-F & CTGATGAAGAAGTCGATGAGATG \\
\hline SICaM2-R & AGACAAGAGCCTACCCAATGA \\
\hline SICaM3-F & САСАACTTTСТТТTСТССС \\
\hline SICaM3-R & TCCCAACGACCTCATCACAG \\
\hline SICaM4-F & CATTITCACACACACACTA \\
\hline SICaM4-R & TCAGCCTCAGTTGGGTTCT \\
\hline SICaM5-F & ATGACAAACCTAGGCGAGAAGC \\
\hline SICaM5-R & AACAAGAACGAATACACAAGAATC \\
\hline SICaM6-F & ATGAGATGATCCGAGAGG \\
\hline SICaM6-R & AGGCCACTAATATACTTGAACC \\
\hline TRV2 2b-F & ATGCACGAATTACTTAGGAAG \\
\hline TRV2 2b-R & GGTAACCTTACTCACAGAAT \\
\hline TRV1 Rep-F & ATCTCAAGTTGATTTGAGGTT \\
\hline TRV1 Rep-R & TGATCTCTTTGCTTACATCGT \\
\hline SIPR1-F & TCTTGTGAGGCCCAAAATTC \\
\hline SIPR1-R & ATAGTCTGGCCTCTCGCACA \\
\hline SIPR5-F & AATTGCAATTTTAATGGTGC \\
\hline SIPR5-R & TAGCAGACCGTTTAAGATGC \\
\hline SICNGC17-F & CATCATATCCACAGTCTGAT \\
\hline SICNGC17-R & CTCATTTGAACCAATGAAGT \\
\hline SICNGC18-F & CTGAAGATGAAGATGAAGAT \\
\hline SICNGC18-R & GTTCTGTCATCACGACTA \\
\hline SIGSTF2-F & CGGATGGGTGAGTATCGCGTTG \\
\hline SIGSTF2-R & TGTGACACAGGAGTTAGGAAAC \\
\hline SIUEP-F & ATGCAGATCTTCGTGAAAACCC \\
\hline SIUEP-R & TCAATCGCCTCCAGCCTTGTTG \\
\hline
\end{tabular}

Silencing of SICaM2 and SICaM6 in tomato plants reduced resistance to TRV and Pythium aphanidermatum, but not to Pst DC3000 and Xoo

To understand the function of SlCaMs in plant disease resistance, virus-induced gene silencing (VIGS) was performed for SlCaM2 and SlCaM6. A vector containing a fragment of eGFP was used as control in agroinfiltrated plants [26]. Three weeks post agro-infiltration, plants treated with eGFP-control showed no or only very weak mosaic symptoms in some leaves. However, most of the SlCaM2- and SlCaM6-silenced tomato plants displayed obvious mosaic and yellowing symptoms, which were most severe in the SlCaM6-VIGS plants (Figure 6A). Gene expression analysis revealed that transcripts of $T R V_{1}$ replicase and $\mathrm{TRV}_{2} 2 \mathrm{~b}$ genes accumulated over 2 and 25 times higher in these plants compared with eGFP-control plants (Figure 6B).
To check whether the symptoms and viral gene transcript accumulation levels correlated with silencing of SlCaM2 and SlCaM6 genes, transcripts of these genes in the agro-infiltrated plants were quantified with qRTPCR. Result showed that SlCaM2 and SlCaM6 transcripts in the VIGS-treated plants dropped to about 30\% of that in eGFP-control plants (Figure 6C). These results demonstrated that silencing of the SlCaM2 and SlCaM6 genes resulted in TRV viral symptoms and higher level of virus accumulation. Together, these data indicate that SlCaM2 and SlCaM6 may have a role in positively regulating tomato resistance to TRV.

To further understand role of SlCaMs in disease resistance, the silenced tomato plants were inoculated with the host pathogens Pst DC3000 and Pythium aphanidermatum and the nonhost pathogen Xoo, and resistance was evaluated. Nonhost resistance to Xoo in silenced plants was similar to that in eGFP-control plants, as both plants initiated hypersensitive response necrosis in infiltrated areas at $12 \mathrm{hpi}$, and showed complete tissue collapse within 24 hpi (Additional file 3A). Resistance to Pst DC3000 was also not altered significantly in silenced plants when compared with the eGFP-control plants. All genotypes showed necrosis at 12 hpi and died at 36 hpi (Additional file 3B). However, when inoculated with $P$. aphanidermatum, necrotic symptoms of the leaves of SlCaM-silenced plants were significantly more severe than that of eGFP-control plants (Figure 7A). The lesions in the silenced plants, $1.7 \sim 1.8 \mathrm{~cm}$ in diameter, were obviously larger in size than those in control plants, $1.5 \mathrm{~cm}$ in diameter (Figure $7 \mathrm{~B}$ ). This result revealed that the SlCaMs are necessary for enhanced resistance to $P$. aphanidermatum in tomato plants.

\section{Silencing of SICaM2 and SICaM6 in tomato plants altered expression of signaling and defense-related genes}

To probe the molecular mechanisms by which SlCaMs regulate plant resistance, we quantified the expression of two pathogenesis-related (PR) genes PR1 and PR5, SlCNGC17 and SlCNGC18 which encode CNGC type calcium channel proteims, one glutathione transferase (GST) gene SIGSTF2, and an ubiquitin extension protein (UEP) gene by qRT-PCR. Silencing of both $\mathrm{SlCaM}$ genes significantly reduced the expression of $P R$ genes and SICNGC18, but increased that of SlCNGC17. In SlCaM2-silenced plants, the expression of PR1, PR5 and SlCNGC18 decreased by $98 \%, 93 \%$ and $60 \%$, respectively, while that of SlCNGC17 increased by 2.7 times. In SlCaM6-silenced plants, the expression of PR1, PR5 and SlCNGC18 lowered by $56 \%, 91 \%$ and $91 \%$, respectively, while that of SlCNGC17enhanced by 3.2 times. However, silencing of the two SlCaM genes had differential effects on the expression of SlGSTF2 and SIUEP; silencing of SlCaM2 resulted in strongly enhanced expression of both genes by over 6.5 times whereas SlCaM6 silencing reduced expression of 


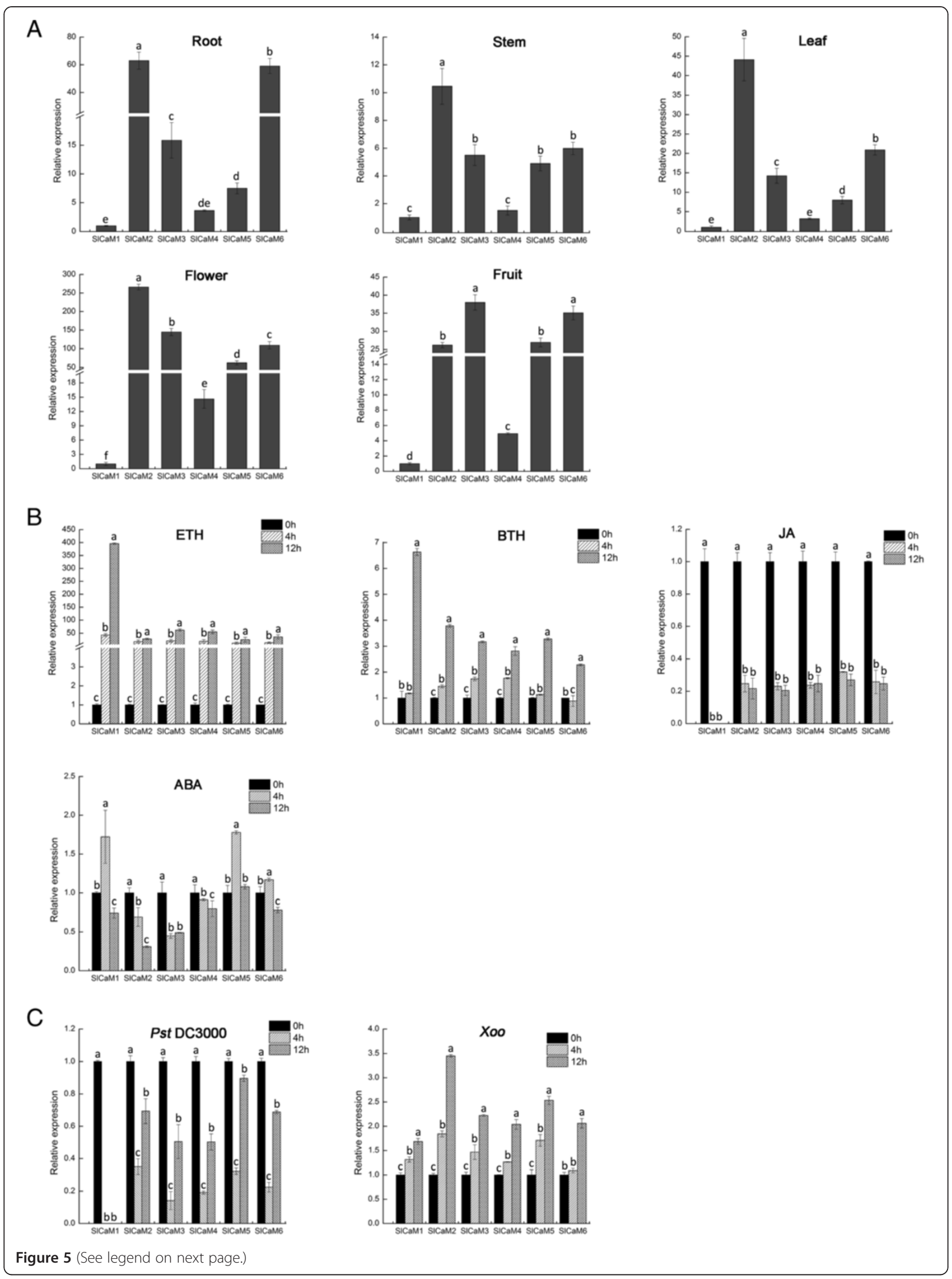


Figure $\mathbf{5}$ Expression profiles of the SICaM genes in plants. Gene expression was analyzed by qRT-PCR. Expression levels relative to S/CaM1 (A) and $0 \mathrm{~h}$ time-point $(\mathbf{B}, \mathbf{C})$ is shown. Significant difference between expression values within the target genes is indicated as different lowercase letters ( $P<0.05$, DMRT). (A) Expression in different organs. (B) Expression in response to different hormone treatments. (C) Expression in response to pathogen inoculation with Pst DC3000 and Xoo.

SlGSTF2 by $29 \%$ and that of SIUEP by $57 \%$ (Figure 8 ). These data indicate that the regulation of cytosolic $\mathrm{Ca}^{2+}$ concentration, ubiquitylation and redox status may be involved in SlCaM-mediated disease resistance, and SlCaM2 and SlCaM6 might employ different molecular mechanisms to regulate disease resistance.

\section{Discussion}

To begin to understand the roles of CaM, the conserved eukaryotic $\mathrm{Ca}^{2+}$ sensor, in plants, we systemically identified the complete CaM gene families in the Solanaceous species tomato, potato and $N$. benthamiana. Previously, 5 full-length and 3 partial potato $\mathrm{CaM}$ genes were identified through screening a potato stolon tip cDNA library with a chicken $C a M$ as probe $[9,27]$. Among the five full-length potato CaMs, PCAM5, PCAM6, PCAM7and PCAM8 encode an identical $\mathrm{CaM}$ sequence, while PCaM1 encodes another $\mathrm{CaM}$ isoform. Thus these five genes encode for two distinct potato CaM isoforms. In the present study, we performed genome-wide analysis for potato CaM genes and identified 4 full-length StCaM genes that we named StCaM1 to StCaM4. These 4 genes encode 3 different StCaM isoforms because StCaM2 and StCaM3 encode identical proteins (Figures 1 and 2). StCaM1 is identical in sequence to PCaM5/6/7/8, while StCaM2/3 and StCaM4 are novel isoforms (Table 1, Figure 3).

Because of the large number of genes encoding proteins with sequence relatedness to $\mathrm{CaM}$, there have been attempts to define canoical CaMs and distinguish them from calmodulin-like (CML) proteins. CaM is one of the most conserved proteins in eukaryotes. For example, the protein sequence identity between vertebrate and plant CaMs is near $90 \%$. In this study, we found that all true CaMs of tomato, potato and N. benthamiana had amino acid sequence identity percentages over $91 \%$, and the sequences of CMLs differed more significantly from the canonical CaMs with the identity percentages of lower than $80 \%$ (Table 1, Additional file 2, Figures 1 and 2). In addition, CaM is 149 amino acid in lengh and carries two pairs of EF-hand motifs, as exemplified by the Solanaceous CaMs identified in this study. We followed the criteria used in a previous analysis of the CaM and $C M L$ gene families of Arabidopsis [5] and identified $\mathrm{CaMs}$ as those proteins should include those that are composed of about 149 amino acids, harbor two pairs of EF-hand motifs, and share over $90 \%$ amino acid sequence identity with known canonical CaMs. Proteins that resemble $\mathrm{CaM}$ in that they have approximately 149
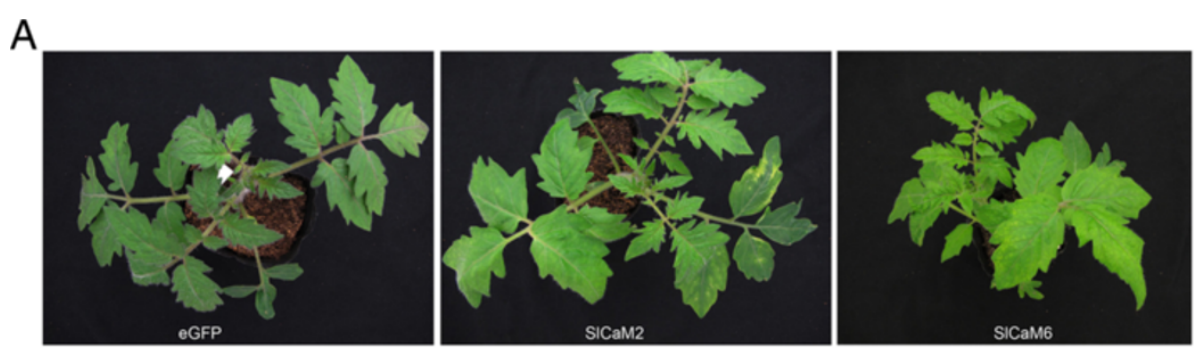

B

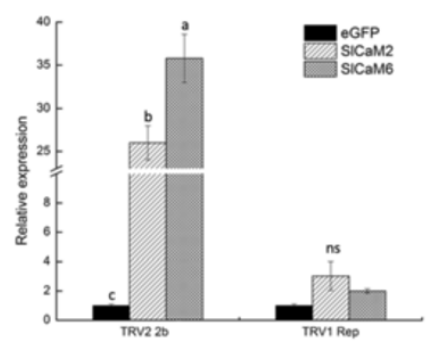

C

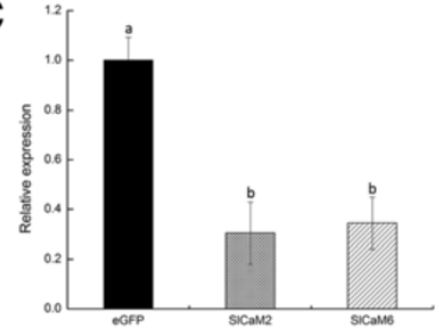

Figure 6 Silencing of SICaM2 and SICaM6 in tomato plants reduced resistance to Tobacco rattle virus (TRV). (A) Phenotypes of the S/CaM gene-silenced plants. Gene silencing analyses were performed using TRV-based vectors. TRV viral symptoms were more severe in S/CaM genesilenced plants compared with the eGFP-control plants. Photographs were taken 3 weeks post agro-infiltration. (B) Detection of transcripts of the $T_{R V}$ replicase and TRV 22 genes in silencing plants by qRT-PCR. (C) Evaluation of gene silencing efficiency. Expression levels of the S/CaM2 and SICaM6 genes in tomato plants were examined by qRT-PCR. Significant difference between expression values within the target genes is indicated as different lowercase letters ( $P<0.05$, DMRT), while no significant difference as "ns". 

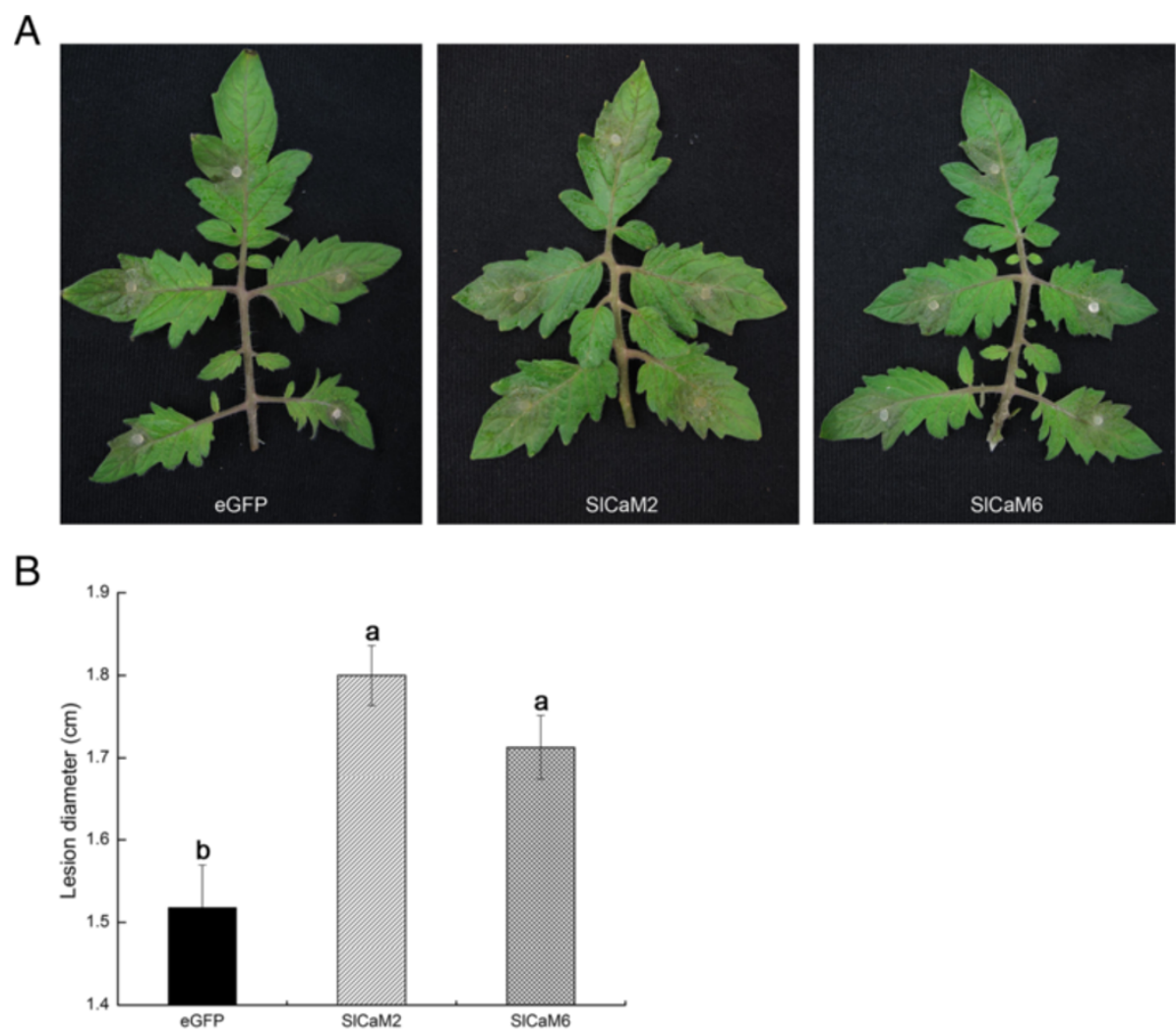

Figure 7 Silencing of SICaM2 and SICaM6 in tomato plants reduced resistance to Pythium aphanidermatum. (A) Disease symptoms of the SICaM gene-silenced plants after inoculation with P. aphanidermatum. Photographs were taken $30 \mathrm{~h}$ post inoculation. (B) Statistical analysis of disease severity. Lesion diameter was recorded and statistically analyzed for all plants. Significant difference between lesion diameter of the plants is indicated as different lowercase letters $(P<0.05$, DMRT).

amino acids and four EF-hand motifs, but share less than $90 \%$ amino acid identity are defined as CaM-like (CML) proteins (Additional file 2). Using these criteria, some previously reported CaMs, such as NtCaM13 [8] and ScaM-4 and SCaM-5 [10], are not true CaMs, but are likely more appropriately referred to as CMLs.

A very unusual characteristic of $\mathrm{CaM}$ gene families is that a small set of genes, usually two to four, encode identical protein isoforms $[4,5]$. In the Solanaceous species used in this study, tomato $S l C a M 3 / 4 / 5$, potato $S t C a M 2 / 3$, $N$. benthamiana $\mathrm{NbCaM1/2/3/4}$ and NbCaM5/6 all encode an identical CaM isoform (Table 1, Figures 1 and 2). The phenomenon of multiple genes encoding identical $\mathrm{CaM}$ isoforms has been described in previous studies; Arabidopsis AtCaM2/3/5, N. tabacum NtCaM3/4/5/6/7/ 8/11/12, rice OsCaM1-1/2/3, soybean GmCaM1/3 all share CaM isoforms $[6-8,10]$. Natural selection is likely acting to keep these protein sequences conserved because the encoding genes are not identical in sequence. The genes differ moderately in the coding sequences (mainly in the third nucleotides, wobble base, of the amino acid coding triplets, Figure 2), bear distinct $5^{\prime}$ upstream sequences (sequence data not shown), carry distinct introns with various sizes and sequences, and are located on different chromosomes (Table 1). This strong conservation argues that $\mathrm{CaM}$ plays critical roles in plant biological processes and that plants may need more than one copy of the $\mathrm{CaM}$ gene to execute essential functions. In addition, this phenomenon may also reflect a strategy of plants to evolve functional gene paralogs. These genes can be gained through sequence exchange among chromosomes. It is likely that all the CaM gene copies are functional because of the strong sequence conservation. However, it is likely that the different genes may respond differentially to stimuli since they contain different upstream sequences and introns. As an example, we found that tomato $\mathrm{SlCaM} 3 / 4 / 5$ genes were expressed at different levels in plant tissues and in response to pathogens (Figure 5). The multiple CaM genes, which encode identical protein isoforms may be related to similar situations in which there are gene families that encode similar, but not identical proteins, such as those involved in disease resistance (R) $[28,29]$ and encoding GST [30]. In cases where multiple genes encode closely related proteins, tandem gene arrangement and/or gene cluster(s) nearby on the same chromosome may facilitate the evolution of genetic diversity [28-30]. 


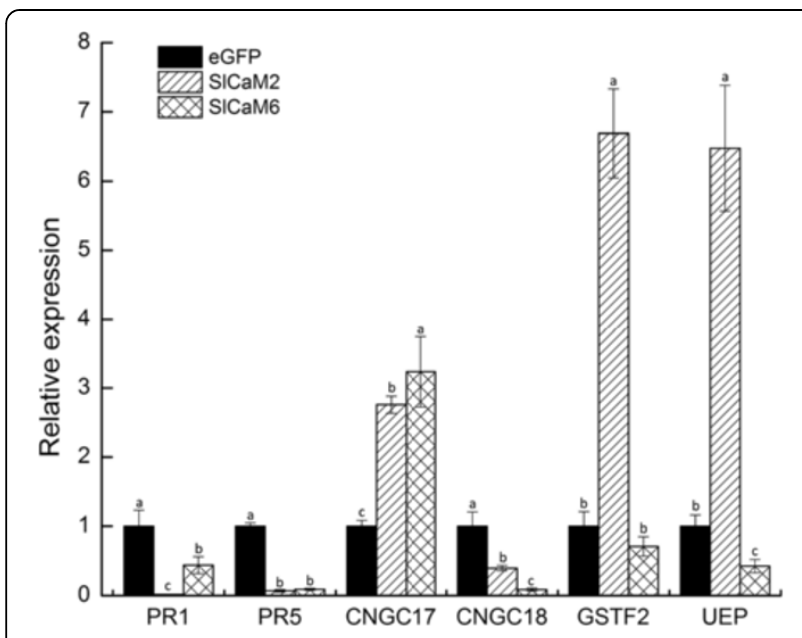

Figure 8 Expression profiles of SIPR, SICNGC, SIUEP and SIGST genes in SICaM-silenced tomato plants. Expression of the genes in tomato plants were examined by qRT-PCR with gene-specific primers listed at Table 3. Significant difference between expression values within the target genes is indicated as different lowercase letters $(P<0.05$, DMRT).

Another intriguing finding in this study is that Solanaceous species seem to have evolved one novel group of CaM genes when compared with Arabidopsis and rice. Phylogenetic analysis reveals that all Arabidopsis and rice $\mathrm{CaM}$ protein isoforms form one clade; however, the CaMs of Solanaceous species separated into two groups, one of them belong to the same clade as that of Arabidopsis and rice $\mathrm{CaMs}$, while the other group members are unique (Figure 4). This classification of CaMs is supported not only by the amino acid sequence similarity but also by the gene structure data. All group I CaM genes contain a single intron, while group II CaMs have three introns (Figure 3). These data suggest the possibility that the different groups of CaMs may play distinct roles in plant biological processes.

Roles for plant CaMs in growth, development and stress resistance have been widely discussed. However, a function for CaMs in plant disease resistance remains not fully explored. In this study, we found that silencing of two SlCaM genes significantly altered signaling and defense-related gene expression, and reduced the resistance in tomato to TRV and the important oomycete pathogen Pythium aphanidermatum (Figures 6, 7 and 8). Therefore, the SlCaMs are important in viral and oomycete resistance. The molecular mechanisms by which CaMs may regulate disease resistance are unknown. We found in this study that silencing of SlCaM2 and SlCaM6 genes significantly reduced the expression of SlCNGC18, but increased that of SlCNGC17, and differentially altered the expression of SIGSTF2 and SIUEP genes (Figure 8). These results provide a hint that regulation of cytosolic $\mathrm{Ca}^{2+}$ concentration, ubiquitylation and redox status may be involved in SlCaM- mediated disease resistance, and SlCaM2 and SlCaM6 might employ different molecular mechanisms to regulate disease resistance.

\section{Conclusions}

The CaM gene families in Solanaceous species tomato, $N$. benthamiana and potato were identified. Tomato, potato and $N$. benthamiana genomes contain multiple CaM genes of high sequence conservation. Solanaceous species has evolved one new group of CaM genes, with distinct gene structure. Whether the different CaM groups play distinct roles remains to be analyzed.

Reduced expression of SlCaM genes SlCaM2 and SlCaM6 impaired resistance of tomato to TRV and the important oomycete pathogen Pythium aphanidermatum, demonstrating that these SlCaMs play important roles in plant disease resistance to a variety of pathogens. Finally, our results suggest that SlCaM2 and SlCaM6 may employ different molecular mechanisms to regulate disease resistance.

\section{Methods}

Identification of CaM genes in Solanaceous species

To find CaM genes in Solanaceous species, all four Arabidopsis and three rice CaM protein sequences were collected trough searching the genome sequence databases TAIR (The Arabidopsis Information Resource, http://www. arabidopsis.org/) and Rice Genome Annotation Database (http://rice.plantbiology.msu.edu/). All retrieved AtCaM and OsCaM protein sequences were used to TBLASTN search the genome databases of Solanaceous species including tomato, potato and Nicotiana benthamiana in Solanaceae Genomics Network (http://solgenomics.net/). All retrieved non-redundant sequences were collected, and subjected to domain analysis by using the Pfam (http://pfam.sanger.ac.uk/) and Conserved Domain Database (CDD) (http://www.ncbi.nlm.nih.gov/cdd) programs. These sequences were compared with Arabidopsis canonical CaM protein AtCaM2 using ClustalX 2.01 program [31] with default settings and were viewed by GeneDoc. Those containing two pairs of EF-hand motifs, displaying amino acid sequence identity of over $90 \%$ to AtCaM2 and having a size of about 149 amino acids were recognized as CaM proteins. CaMs in a given species were named in accordance with sequence similarity to Arabidopsis CaMs.

\section{Phylogenetic and gene structure analyses of CaM genes}

CaMs from different plant species were aligned by using ClustalX 2.01 program [31] with default settings. The un-rooted phylogenetic trees were constructed based on alignments using MEGA 5.0 [32] with the maximum likelihood (ML) method. The bootstrap analysis was carried out setting up 1000 replicates. Exon-intron 
structure analyses were carried out using the Gene Structure Display Server (GSDS) program with default settings [33].

\section{Bioinformatics prediction of regulators of SICaM gene expression}

The upstream $1000 \mathrm{bp}$ sequence of $S l C a M$ genes were searched for a variety of cis-acting elements by 'Signal Scan Search' program in the PLACE database (http:// www.dna.affrc.go.jp/PLACE/).

\section{Construction of the virus induced gene silencing (VIGS) constructs}

The coding regions of the SlCaM genes are highly conserved. To specifically silence a target gene member, a gene-specific 3' UTR sequence of each SlCaM gene was inserted into TRV-based VIGS vector pYL156 according to the following procedure. A 171 bp 3' UTR fragment of SlCaM2 gene (Solyc10g081170.1.1) was amplified by PCR from tomato using primers VSlCaM2-F (gcgaattcTT CCATTATCCTCTTGTTACA, a EcoRI site was introduced) and VSlCaM2-R (ttggatccGTAGAGATCACACC ACTCATAC, a Bam HI site was introduced), while a 286 bp fragment of SlCaM6 gene (Solyc03g098050.2.1) was amplified by primers VSlCaM6-F (gcgaattcTGACTTT AAGATTCTGTTAGCT, a EcoRI site was introduced) and VSICaM6-R (ttggatccGATATTACCAATGAACTATCTA, a Bam HI site was introduced). The resulting PCR product was cloned into pYL156 with Eco RI/Bam HI, and confirmed by sequencing. The recombinant constructs were transformed into Agrobacterium tumefaciens (strain GV3101) for VIGS analysis.

\section{VIGS manipulation procedure}

VIGS analysis in tomato was conducted as described

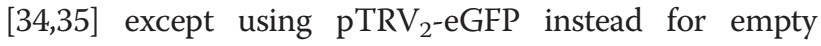
pTRV2 as a negative control vector so that the viral symptom can be repressed efficiently [26]. Briefly, agro-inoculi harboring $\mathrm{pTRV}_{1}$ and $\mathrm{TRV}_{2}$-eGFP or $\mathrm{pTRV}_{2}-\mathrm{SlCaM}$ were vacuum infiltrated into cotyledons of seedlings just developing the first true leaves. The agro-inoculated plants were grown in a plant growth chamber at $21^{\circ} \mathrm{C}$ with a 16 $\mathrm{h} / 8 \mathrm{~h}$ light/dark regime. Three weeks later, the plants were subjected to disease resistance analyses, and leaves were sampled to check the gene silencing efficiency and the accumulation of $T R V$ gene transcripts by qRT-PCR with specific primers (Table 3 ).

\section{Plant materials for expression analysis}

Tomato plants (cultivar Suhong2003) were grown in growth chambers at $28^{\circ} \mathrm{C}$ with a $16 \mathrm{~h} / 8 \mathrm{~h}$ light/dark daily cycle. Different organs including roots, stems, leaves flowers and fruits were collected from 4-month-old tomato plants. Harvested organs were immediately frozen in liquid nitrogen and stored at $-80^{\circ} \mathrm{C}$.

For hormone treatment, leaves of 7- to 8-week-old tomato seedlings were sprayed with $100 \mu \mathrm{M}$ abscisic acid (ABA), $10 \mathrm{mM}$ ethephon (ETH), $200 \mu \mathrm{M}$ jasmonic acid (JA), $350 \mu \mathrm{M}$ benzothiadiazole (BTH), or sterilized water as control, respectively. Leaves were sampled at $4 \mathrm{~h}$ and $12 \mathrm{~h}$ post treatment for analysis of SlCaM gene expression.

For pathogen inoculation, the bacterial pathogens Pseudomonas syringae pv. tomato DC3000 (Pst DC3000) and Xanthomonas oryzae pv. oryzae (Xoo) were incubated overnight at $28^{\circ} \mathrm{C}$ on King's medium B plates containing rifampicin $(50 \mu \mathrm{g} / \mathrm{mL})$ and kanamycin $(50 \mu \mathrm{g} / \mathrm{mL})$ and NA liquid medium respectively. The bacterial cells were collected by centrifugation and then diluted into suspensions to a concentration of $\mathrm{OD}_{600}=0.002$ and 0.5 using 10 $\mathrm{mM} \mathrm{MgCl}_{2}$ buffer or sterilized $\mathrm{ddH}_{2} \mathrm{O}$, respectively. The prepared bacterial solution $\left(10 \mathrm{mM} \mathrm{MgCl}_{2}\right.$ buffer or sterilized $\mathrm{ddH}_{2} \mathrm{O}$ as controls) was infiltrated into leaves of 7- to 8 -week-old tomato plants. Samples were taken at $0 \mathrm{~h}, 4 \mathrm{~h}$ and $8 \mathrm{~h}$ after infiltration with Xoo and $0 \mathrm{~h}, 4 \mathrm{~h}$ and $12 \mathrm{~h}$ with Pst DC3000, respectively, for gene expression analysis.

\section{Gene expression analysis with real time PCR}

Total RNA was extracted by Trizol regent (TAKARA, Japan) according to the manufacturer's instructions. RNA was treated with DNase I (TAKARA, Japan) and reverse-transcribed into cDNA using the PrimeScript RT regent kit (TAKARA, Japan). The obtained cDNAs were used for gene expression detection analysis with real time quantitative PCR. RT-PCR was conducted in StepOne Real-Time PCR System (Applied Biosystems, USA) using SYBER Premix Ex Taq reagents (TAKARA, Japan) following the program: $95^{\circ} \mathrm{C}$ for $30 \mathrm{~s}, 95^{\circ} \mathrm{C}$ for $5 \mathrm{~s}$ and $60^{\circ} \mathrm{C}$ for $45 \mathrm{~s}$ for 40 cycles. To normalize the sample variance, $18 S \mathrm{rDNA}$ gene was served as the internal control. Relative gene expression values were calculated using the $2^{-\Delta \Delta \mathrm{Ct}}$ method. To ensure gene-specificity of RT-PCR, primers were designed according to the $5^{\prime}$ and 3' UTR regions of the SlCaM genes. The primers used for gene expression analysis are listed at Table 3.

The experiments were conducted three times, each containing three replicates for all genes. For the statistical analysis of the gene expression data, ANOVA (analysis of variance) analysis was performed with SPSS software (Version 19.0, IBM, USA). Significance of the differences between mean values was determined with Duncan's multiple range test (DMRT).

\section{Plant disease resistance analysis}

The VIGS-treated plants were subjected to disease resistance evaluation. Bacterial pathogens Pst DC3000 and Xoo 
were performed as described above. The oomycete pathogen Pythium aphanidermatum were grown at $25^{\circ} \mathrm{C}$ on potato dextrose agar (PDA) medium for $2 \mathrm{~d}$. PDA plugs of $3 \mathrm{~mm}$ in diameter were taken from the outside circle containing most actively young mycelia, and were put on the newly developed leaves of the VIGS-treated plants. After inoculation, the plants were maintained at high relative humidity for $2 \mathrm{~d}$. Disease or HR symptoms were investigated. Size of the necrosis was recorded and photographs were taken accordingly.

Resistance to each pathogen was analyzed in at least six plants per experiment, and the experiment was repeated twice.

\section{Additional files}

\section{Additional file 1: Alignment profile of $\mathrm{NbCaM}(\mathrm{A}), \mathrm{StCaM}(\mathrm{B})$ and} SICaM (C) coding sequences. The accession numbers for the CaM genes were listed at Table 1.

Additional file 2: CML, CDPK and other sequences retrieved from BLAST searches against SGN databases with Arabidopsis and rice CaM protein sequences.

Additional file 3: Hypersensitive response symptoms in SICaM2and SICaM6-silenced plants inoculated with bacterial pathogens Pst DC3000 and Xoo. Plants infiltrated with Agrobacterium suspensions carrying an EGFP control vector were served as control plants.

Photographs were taken at $36 \mathrm{~h}$ post Pst DC3000 inoculation (A) and 48 $h$ post $X_{00}$ inoculation (B).

\section{Abbreviations}

ABA: Abscisic acid; BTH: Benzothiadiazole; CaM: Calmodulin; CNGC: Cyclic nucleotide gated channel; ETH: Ethephon; GST: Glutathione transferase; JA: Jasmonic acid; NtCaM: Nicotiana benthamiana calmodulin; PR: Pathogenesis-related; Pst DC3000: Pseudomonas syringae pv. tomato DC3000; SICaM: Solanum lycopersicum calmodulin; StCaM: Solanum tuberosum calmodulin; Xoo: Xanthomonas oryzae pv. oryzae; UEP: Ubiquitin extension protein; VIGS: Virus-induced gene silencing.

\section{Competing interests}

The authors declare that they have no competing interests.

\section{Authors' contributions}

The project was coordinated by XZC. YZ and WL conducted the bioinformatics and phylogenetic analyses. YZ, YPX and JYC carried out the gene expression assays and VIGS analyses. YZ designed and performed the statistical analysis. XZC conceived of the study, and participated in its design and coordination. JB provided advice on protein classification. XZC, JB and YZ prepared the manuscript. All authors read and approved the final manuscript.

\section{Acknowledgements}

This work was financially supported by grants from the National Basic Research Program of China (no. 2009CB119000), the Special Fund for Agro-scientific Research in the Public Interest (no. 201103016), the Program for Changjiang Scholars and Innovative Research Team in University (no. IRT0943), the Program for New Century Excellent Talents in University (no. NCET-08-0485), the Program for New Century 151 Talents of Zhejiang Province, and the US National Science Foundation (Grant No. MCB 0817976 to JB).

\section{Author details}

'Institute of Biotechnology, College of Agriculture and Biotechnology, Zhejiang University, 866 Yu Hang Tang Road, Hangzhou 310058, China. ${ }^{2}$ Center of Analysis and Measurement, Zhejiang University, 866 Yu Hang
Tang Road, Hangzhou 310058, China. ${ }^{3}$ Department of Biochemistry and Cell Biology, Rice University, Houston, TX 77005-1892, USA.

Received: 31 January 2013 Accepted: 24 April 2013

Published: 27 April 2013

\section{References}

1. DeFalco TA, Bender KW, Snedden WA: Breaking the code: $\mathrm{Ca}^{2+}$ sensors in plant signalling. Biochem J 2010, 425:27-40

2. Reddy ASN, Ali GS, Celesnik H, Day IS: Coping with stresses: roles of calcium- and calcium/calmodulin-regulated gene expression. Plant Cell 2011, 23:2010-2032.

3. Galon Y, Finkler A, Fromm H: Calcium-regulated transcription in plants. Mol Plant 2010, 3:653-669.

4. McCormack E, Tsai YC, Braam J: Handling calcium signaling: Arabidopsis CaMs and CMLs. Trends Plant Sci 2005, 10:383-389.

5. McCormack E, Braam J: Calmodulins and related potential calcium sensors of Arabidopsis. New Phytol 2003, 159:585-598.

6. Boonburapong B, Buaboocha T: Genome-wide identification and analyses of the rice calmodulin and related potential calcium sensor proteins. BMC Plant Biol 2007, 7:4.

7. Gawienowski MC, Szymanski D, Perera IY, Zielinski RE: Calmodulin isoforms in Arabidopsis encoded by multiple divergent messenger-RNAs. Plant Mol Biol 1993, 22:215-225.

8. Yamakawa H, Mitsuhara I, Ito N, Seo S, Kamada H, Ohashi Y: Transcriptionally and post-transcriptionally regulated response of 13 calmodulin genes to tobacco mosaic virus-induced cell death and wounding in tobacco plant. Eur J Biochem 2001, 268:3916-3929.

9. Takezawa D, Liu ZH, An G, Poovaiah BW: Calmodulin gene family in potato-developmental and touch-induced expression of the messengerRNA encoding a novel isoform. Plant Mol Biol 1995, 27:693-703.

10. Lee SH, Kim JC, Lee MS, Heo WD, Seo HY, Yoon HW, Hong JC, Lee SY, Bahk JD, Hwang I, Cho MJ: Identification of a novel divergent calmodulin isoform from soybean which has differential ability to activate calmodulin-dependent enzymes. J Biol Chem 1995, 270:21806-21812.

11. Wang L, Tsuda K, Sato M, Cohen JD, Katagiri F, Glazebrook J: Arabidopsis $\mathrm{CaM}$ binding protein CBP60g contributes to MAMP-induced SA accumulation and is involved in disease resistance against Pseudomonas syringae. PLoS Pathogen 2009, 5:e1000301.

12. Parvin S, Lee OR, Sathiyaraj G, Khorolragchaa A, Kim YJ, Devi BSR, Yang DC: Interrelationship between calmodulin $(\mathrm{CaM})$ and $\mathrm{H}_{2} \mathrm{O}_{2}$ in abscisic acidinduced antioxidant defense in the seedlings of Panax ginseng. Mol Biol Rep 2012, 39:7327-7338.

13. Kushwaha R, Singh A, Chattopadhyay S: Calmodulin7 plays an important role as transcriptional regulator in Arabidopsis seedling development. Plant Cell 2008, 20:1747-1759.

14. Landoni M, De Francesco A, Galbiati M, Tonelli C: A loss-of-function mutation in Calmodulin2 gene affects pollen germination in Arabidopsis thaliana. Plant Mol Biol 2010, 74:235-247.

15. Liao $\mathrm{WB}$, Zhang $\mathrm{ML}$, Huang $\mathrm{GB}, \mathrm{Yu} \mathrm{JH}: \mathrm{Ca}^{2+}$ and $\mathrm{CaM}$ are involved in NOand $\mathrm{H}_{2} \mathrm{O}_{2}$-induced adventitious root development in marigold. J Plant Growth Regul 2012, 31:253-264.

16. Phean-O-pas S, Punteeranurak P, Buaboocha T: Calcium signalingmediated and differential induction of calmodulin gene expression by stress in Oryza sativa L. J Biochem Mol Biol 2005, 38:432-439.

17. Yoo JH, Park CY, Kim JC, Heo WD, Cheong MS, Park HC, Kim MC, Moon BC, Choi MS, Kang YH, Lee JH, Kim HS, Lee SM, Yoon HW, Lim CO, Yun DJ, Lee $S Y$, Chung WS, Cho MJ: Direct interaction of a divergent CaM isoform and the transcription factor, MYB2, enhances salt tolerance in Arabidopsis. J Biol Chem 2005, 280:3697-3706.

18. Fang RJ, Hu DQ, Zhang YH, Li L, Zhao WG, Liu L, Cheng JL, Qi JL, Yang YH: Sequence analysis and expression of the calmodulin gene, MCaM-3, in mulberry (Morus L.). Genes Genom 2011, 33:97-103.

19. Saeng-ngam S, Takpirom W, Buaboocha T, Chadchawan S: The role of the OsCam1-1 salt stress sensor in ABA accumulation and salt tolerance in rice. J Plant Biol 2012, 55:198-208.

20. Heo WD, Lee SH, Kim MC, Kim JC, Chung WS, Chun HJ, Lee KJ, Park CY, Park HC, Choi JY, Cho MJ: Involvement of specific calmodulin isoforms in salicylic acid-independent activation of plant disease resistance responses. Proc Natl Acad Sci USA 1999, 96:766-771. 
21. Park $C Y$, Heo WD, Yoo JH, Lee JH, Kim MC, Chun HJ, Moon BC, Kim IH, Park HC, Choi MS, Ok HM, Cheong MS, Lee SM, Kim HS, Lee KH, Lim CO, Chung WS, Cho MJ: Pathogenesis-related gene expression by specific calmodulin Isoforms is dependent on NIM1, a key regulator of systemic acquired resistance. Mol Cells 2004, 18:207-213.

22. Choi HW, Lee DH, Hwang BK: The pepper calmodulin gene cacam 1 is involved in reactive oxygen species and nitric oxide generation required for cell death and the defense response. Mol Plant Microbe Interact 2009, 22:1389-1400.

23. Takabatake R, Karita E, Seo S, Mitsuhara I, Kuchitsu K, Ohashi Y: Pathogeninduced calmodulin isoforms in basal resistance against bacterial and fungal pathogens in tobacco. Plant Cell Physiol 2007, 48:414-423.

24. Du LQ, Ali GS, Simons KA, Hou JG, Yang TB, Reddy ASN, Poovaiah BW: $\mathrm{Ca}^{2+} /$ calmodulin regulates salicylic-acid-mediated plant immunity. Nature 2009, 457:1154-1158.

25. Batistic $\mathrm{O}$, Kudla J: Analysis of calcium signaling pathways in plants. BBA-Gen Subjects 1820, 2012:1283-1293.

26. Cheng WS, Xu QF, Li F, Xu YP, Cai XZ: Establishment of a suitable control vector for Tobacco rattle virus-induced gene silencing analysis in Nicotiana benthamiana. J Zhejiang Univ (Agric \& Life Sci) 2012, 38:10-20,

27. Jena PK, Reddy ASN, Poovaiah BW: Molecular-cloning and sequencing of a CDNA for plant calmodulin - signal-induced changes in the expression of calmodulin. Proc Natl Acad Sci USA 1989, 86:3644-3648.

28. Meyers BC, Kaushik S, Nandety RS: Evolving disease resistance genes. Curr Opin Plant Biol 2005, 8:129-134.

29. Friedman AR, Baker BJ: The evolution of resistance genes in multi-protein plant resistance systems. Curr Opin Genet Dev 2007, 17:493-499.

30. Lan T, Yang ZL, Yang X, Liu YJ, Wang XR, Zeng QY: Extensive functional diversification of the Populus glutathione S-transferase supergene family. Plant Cell 2009, 21:3749-3766.

31. Larkin MA, Blackshields G, Brown NP, Chenna R, McGettigan PA, McWilliam $H$, Valentin F, Wallace IM, Wilm A, Lopez R, Thompson JD, Gibson TJ, Higgins DG: Clustal W and Clustal X version 2.0. Bioinformatics 2007, 23:2947-2948.

32. Tamura K, Peterson D, Peterson N, Stecher G, Nei M, Kumar S: MEGA5: molecular evolutionary genetics analysis using maximum likelihood, evolutionary distance, and maximum parsimony methods. Mol Biol Evol 2011, 28:2731-2739.

33. Guo AY, Zhu QH, Chen X, Luo JC: GSDS: a gene structure display server. Yi Chuan 2007, 29:1023-1026.

34. Cai XZ, Wang $C C, X u Y P, X u$ QF, Zheng Z, Zhou X: Efficient gene silencing induction in tomato by a viral satellite DNA vector. Virus Res 2007, 125:169-175.

35. Wang CC, Cai XZ, Wang XM, Zheng Z: Optimisation of tobacco rattle virus-induced gene silencing in Arabidopsis. Funct Plant Biol 2006, 33:347-355.

doi:10.1186/1471-2229-13-70

Cite this article as: Zhao et al: Genome-wide identification and functional analyses of calmodulin genes in Solanaceous species. BMC Plant Biology 2013 13:70.

\section{Submit your next manuscript to BioMed Central and take full advantage of:}

- Convenient online submission

- Thorough peer review

- No space constraints or color figure charges

- Immediate publication on acceptance

- Inclusion in PubMed, CAS, Scopus and Google Scholar

- Research which is freely available for redistribution

Submit your manuscript at www.biomedcentral.com/submit 